\title{
Mycoplasma pneumoniae, a trigger for Weston Hurst syndrome
}

\section{OPEN}

Rick Magun, MBBS, MSc Chris P. Verschoor, PhD

Dawn M.E. Bowdish, $\mathrm{PhD}$

John Provias, FRCP, MD

Correspondence to Rick Magun: rmagun@gmail.com

\section{ABSTRACT}

Objective: We report a case of Mycoplasma pneumoniae infection as one possible trigger for Weston Hurst syndrome (acute hemorrhagic leukoencephalitis), a rare disorder of microvascular injury often described as a postinfectious complication of an upper respiratory illness.

Methods: This is a case of a 27-year-old man presenting with a Glasgow Coma Scale score of 3 and an acute head CT revealing extensive vasogenic edema in the right hemisphere associated with mass effect in the context of a recent upper respiratory illness. Right frontal biopsy was performed on day 2, which showed acute cerebritis, and the patient was aggressively treated with antibiotics. However, over the next 5 days from presentation, the vasogenic edema increased, leading ultimately to brain herniation and death.

Results: A full autopsy was performed at 5 days from presentation, which showed areas of vessel wall fibrinoid necrosis throughout the right hemisphere as well as, but less so, in the left frontal lobe and pons. Chest x-ray on presentation revealed atypical pneumonia, blood tests were positive for cold agglutinins, and at full autopsy, there was myocarditis, all in keeping with recent M pneumoniae infection. DNA obtained from lung and diseased brain (postmortem) was positive for Mycoplasma providing more direct evidence for brain invasion by this organism as the ultimate trigger for Weston Hurst syndrome.

Conclusions: This is a rare case report of Weston Hurst syndrome having both initial brain biopsy on day 2 and full autopsy results on day 5 of presentation revealing important clinical clues about the pathogenesis of this often fatal disorder. Neurol Neuroimmunol Neuroinflamm 2016;3:e187; doi: 10.1212/NXI.0000000000000187

\section{GLOSSARY}

AHLE = acute hemorrhagic leukoencephalitis; HSV = herpes simplex virus; $\mathbf{I g}=$ immunoglobulin.

Weston Hurst syndrome is a rare, acute disorder characterized by diffuse fibrinoid necrosis of vessels and/or perivascular demyelination in the CNS. Previous reports suggest it is a hyperacute form of acute disseminated encephalomyelitis. Also known as acute necrotizing encephalopathy, acute hemorrhagic encephalomyelitis, acute hemorrhagic leukoencephalitis (AHLE), WestonHurst syndrome, or Hurst disease, AHLE is a rare disorder with fewer than 100 cases reported in the medical literature as of 2014. ${ }^{1,2}$

The initial presentation of AHLE involves a rapid deterioration and often death occurring within days to weeks of the first symptom signifying the poor prognosis for this disorder. It is believed to be a postinfectious encephalopathy but the trigger, thought to be a viral or bacterial respiratory infection, remains unclear. It is thought that the pathogen induces an autoimmune cross-reaction against myelin and/or other antigens; however, this has yet to be fully proven. ${ }^{3}$ Pathologic features previously described include vascular necrosis, focal demyelination, edema, inflammatory meningeal infiltrates, and focal hemorrhagic areas. The prognosis remains poor; most patients die within 2 to 4 days after symptom onset.

From the Department of Neurology (R.M.), McMaster Immunology Research Centre (C.P.V., D.M.E.B.), and Department of Pathology and Molecular Medicine (Neuropathology) (J.P.), McMaster University, Hamilton, Ontario, Canada.

Funding information and disclosures are provided at the end of the article. Go to Neurology.org/nn for full disclosure forms. The Article Processing Charge was paid by the authors.

This is an open access article distributed under the terms of the Creative Commons Attribution-NonCommercial-NoDerivatives License 4.0 (CC BY-NC-ND), which permits downloading and sharing the work provided it is properly cited. The work cannot be changed in any way or used commercially. 
Figure 1 Summary of clinical presentation
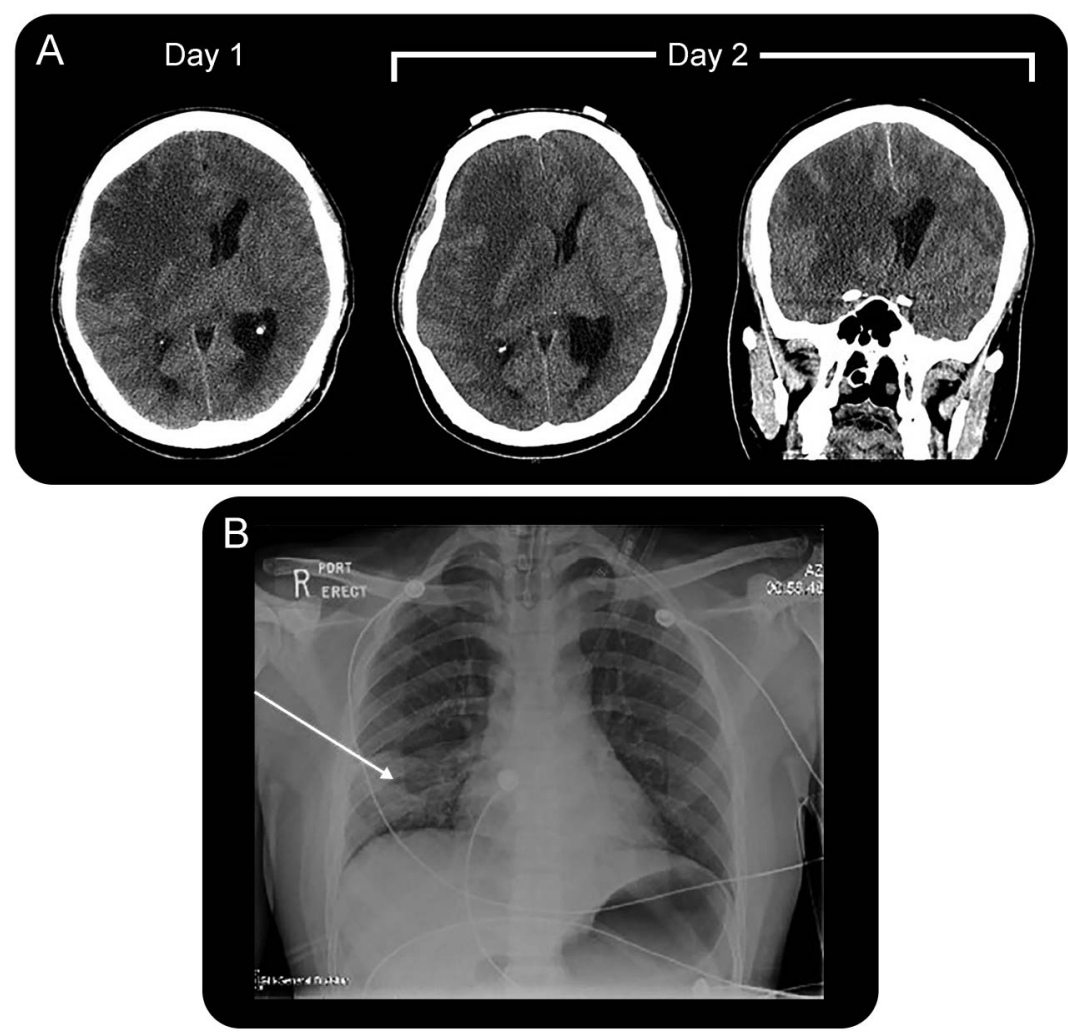

(A) Head CT on days 1 and 2 showed extensive vasogenic edema in the right temporal-parietal region, a focal hypodensity in the right frontal region associated with mass effect, and subfalcine herniation to the left with early central downward herniation. Therefore, an urgent right-sided craniectomy was performed to relieve the pressure and obtain a biopsy of the right frontal region. (B) Chest $x$-ray on day 2 showed patchy congestion consistent with a right lower lobe pneumonia as well as pulmonary edema. Later, autopsy results at day 5 confirmed these findings and also showed mucoid purulent secretions in the bronchial tree. Myocarditis was also noted at autopsy with a primary neutrophilic reaction. Nasopharyngeal swab was negative for enteroviruses and respiratory viruses via PCR. Cold agglutinins were positive at a titer of 64 when tested against adult cells at $4^{\circ} \mathrm{C}$

To date, the pathogenesis of this disorder has remained elusive. Herein, we describe Mycoplasma pneumoniae with brain invasion as a trigger for Weston Hurst syndrome. This first triggers a neutrophil reaction as seen at biopsy on day 2, followed by a macrophage predominant immune reaction at autopsy on day 5 .

CASE This is a case of a 27-year-old man with a 2day history of cough, headache, and coryza and documented temperature of $39.5^{\circ} \mathrm{C}$. Before this, he had been well with no preexisting medical problems. He did not drink alcohol, had no history of IV drug use, and was a nonsmoker. He emigrated from Taiwan to Canada in 1993. There was no recent travel or sick contacts and no family history of neurologic disorders. He was seen by an outpatient family medicine clinic and received antibiotics (clarithromycin) and 4 hours later presented to the emergency room with a Glasgow Coma Scale score of 3 requiring immediate intubation. Head CT showed right frontal edema with mass effect (figure 1A). Examination revealed a temperature of $39.1^{\circ} \mathrm{C}$, blood pressure of $150 / 70 \mathrm{~mm} \mathrm{Hg}$, and oxygen saturation of $95 \%$. His neurologic examination showed midsized nonreactive pupils, normal corneal reflex, no gag reflex, and extension of all 4 limbs to painful stimuli. A head CT showed extensive vasogenic edema in the right frontal-parietal region, a focal hypodensity in the right frontal area associated with mass effect, and subfalcine herniation to the left with early central downward herniation (figure 2). Therefore, an urgent right-sided craniectomy was performed with a partial right frontal lobectomy and insertion of a ventricular drain. As expected, his intracranial pressure was raised. Initial brain biopsy of the right frontal region on day 2 showed acute cerebritis (figure 3).

He was admitted to intensive care postoperatively, and our infectious disease team was consulted and suggested a differential diagnosis of pneumonia with hematogenous spread to the brain, or a primary encephalitis. CSF was taken on day 2 from the ventricle drain and sent to microbiology only and unfortunately no biochemistry was obtained including protein level, glucose, and cell count. CSF was negative for Gram stain and culture as well as for herpes simplex virus (HSV)-1 and -2 via PCR. Blood cultures were also taken on day 2 via line and peripherally and showed no growth after 5 days. Nasopharyngeal swab taken on day 2 was negative for respiratory viruses via PCR. HIV serology tested on day 3 was negative for HIV p24 antigen and negative for HIV-1/HIV-2 antibodies. Nevertheless, given his lung $\mathrm{x}$-ray showed consolidation (figure 1B), he was placed on the following antimicrobials: ceftriaxone 2 g IV twice a day, vancomycin 1 g IV every 8 hours, and acyclovir $1 \mathrm{~g}$ IV every 8 hours (HSV status at the time was pending). The patient also received dexamethasone $4 \mathrm{mg}$ IV every 8 hours to reduce vasogenic edema and phenytoin (Dilantin) $300 \mathrm{mg}$ IV daily for seizure prophylaxis. Propofol and fentanyl were also used in the intensive care unit for sedation and analgesia effect. His hemoglobin dropped to $74 \mathrm{~g} / \mathrm{L}$ from a postoperative value of $90 \mathrm{~g} / \mathrm{L}$. Cold agglutinins were identified, but because the bilirubin was normal, it was thought to be secondary to infection rather than hemolytic anemia. International normalized ratio, liver function testing, and creatine were all normal. White blood cell count was $19 \times 10^{9} / \mathrm{L}$ with an absolute neutrophil count of $17.7 \times 10^{\%} / \mathrm{L}$, and platelets were $165 \times 10^{9} / \mathrm{L}$. Despite aggressive therapy, he lost his brainstem reflexes over the next 48 hours and developed diabetes insipidus. He was unfortunately declared brain dead the next day, on 

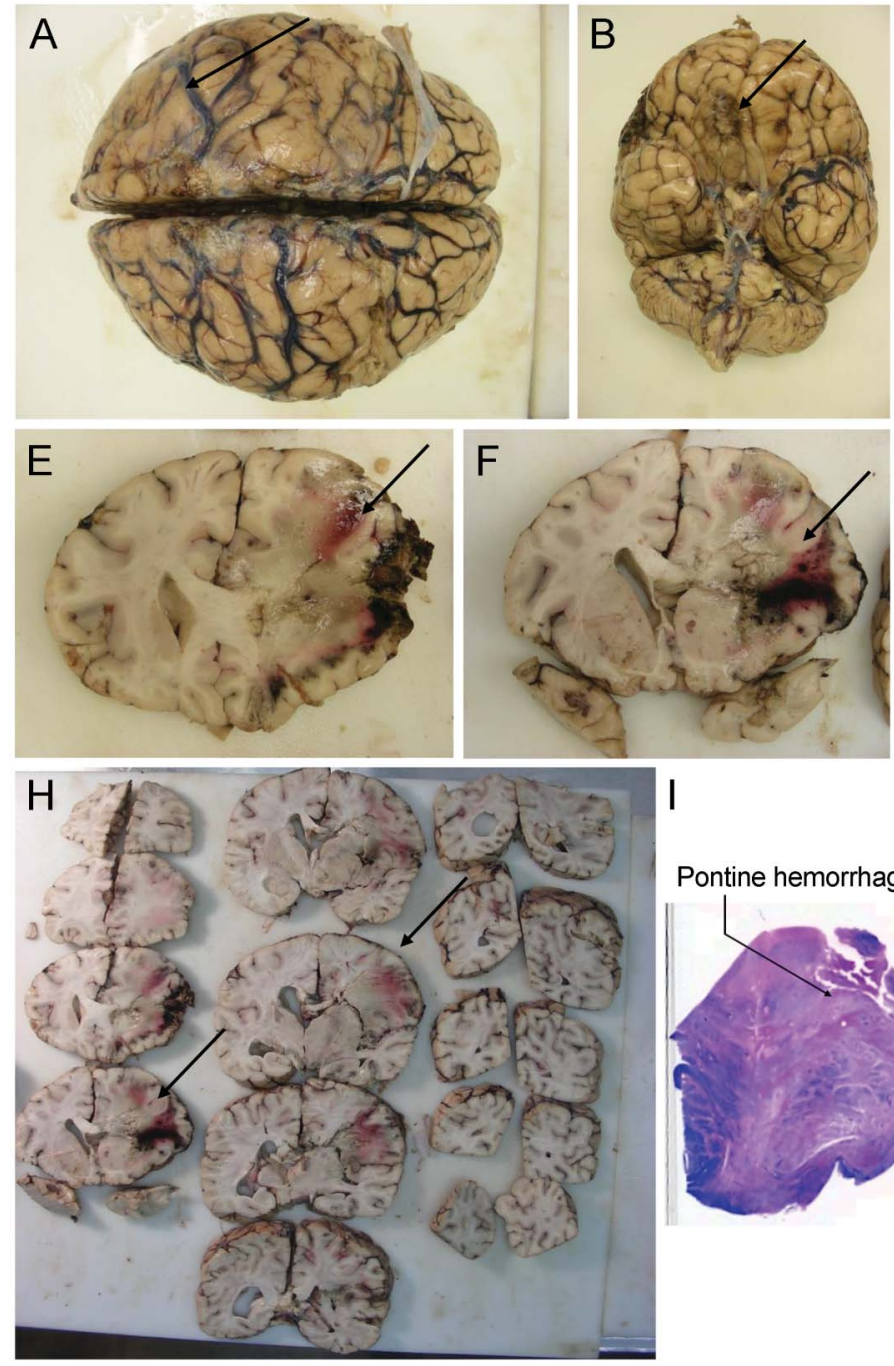
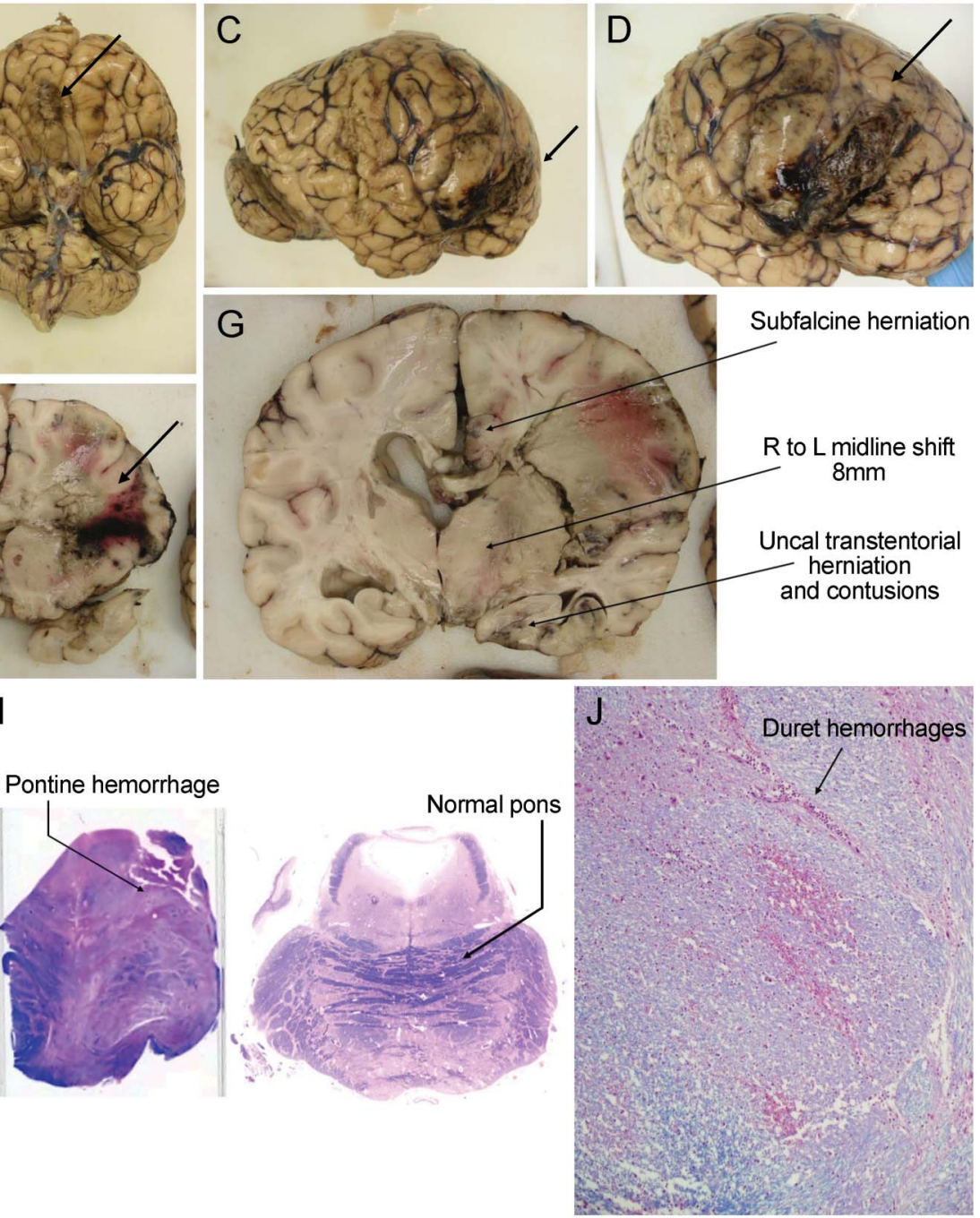

A full Autopsy was performed after the patient died on Day 5 and the brain weight was 1600 grams. There is evidence of a previous right frontal biopsy site. On external examination of the brain there was hemorrhagic necrosis and swelling noted along the right lateral edge of the frontal/temporal/parietal area (arrows, A, C-F, H) with evidence of flattening of the right olfactory tract secondary to increase intracranial pressure (arrow, B). There was subfalcine herniation to the left, with herniation of the cingulate gyrus underneath the edge of the falx cerebri (arrow, G). There was also transtentorial herniation on the right with early signs of Duret's hemorrhages in the pons (arrows, I, J). A normal pons is shown for comparison (I). There was also cerebellar tonsillar herniation noted on the right which was likely the fatal complication.

day 5. Postmortem cultures were taken on day 6 including CSF for Gram stain and culture as well as lung tissue from the right side in the area of consolidation and from the left lung. Brain tissue in the area of hemorrhage, purulent fluid, which was noted in the bladder, and peripheral blood cultures were also sent on day 6 (postmortem). These were all negative for culture and Gram stain.

METHODS Biopsy tissue was placed in $10 \%$ formalin for processing for light microscopy. The brain was fixed in $10 \%$ formalin for approximately 3 weeks and it was then examined grossly and sectioned at $1.5-\mathrm{cm}$ intervals. Sections of the lesions in the white matter, the cerebral cortex, thalamus, basal ganglia, hippocampus, cerebellum, midbrain, pons, and medulla were taken for histologic evaluation. DNA was isolated from lung and brain. A Mycoplasma
PCR Detection Kit from ZmTech Scientifique (Montreal, Canada) was used, which screens up to 117 species of Mycoplasma. Several antibodies were used for immunohistochemistry as follows: a monoclonal mouse anti-human neurofilament immunoglobulin G (IgG) antibody reacting to $70-\mathrm{kDa}$ subunit was used at 1:200 dilution. Rabbit polyclonal myelin basic protein IgG antibody (Ab-1) was obtained from Neo Markers Inc. and used at a 1:100 dilution. A rabbit polyclonal anti-glial fibrillary acidic protein antibody from Dako (Carpinteria, CA) was used at 1:200 dilution. A rabbit polyclonal anti-water channel aquaporin 4 antibody at 1:200 to 1:400 dilution was used (Sigma-Aldrich, St. Louis, MO). A Monoclonal mouse anti-human CD5 antibody was used at 1:200 (Dako). CD3, CD4, CD8, CD20, and CD68 monoclonal mouse antibodies were also ordered from Dako and used as per manufacturer's protocol. Rabbit antihuman ferritin antibody from Dako was used at 1:100 dilution. Polyclonal rabbit HSV-1 and HSV-2 antibodies were used at a dilution of 1:100 (Dako). 
Figure $3 \quad$ Initial brain biopsy and autopsy microscopic findings
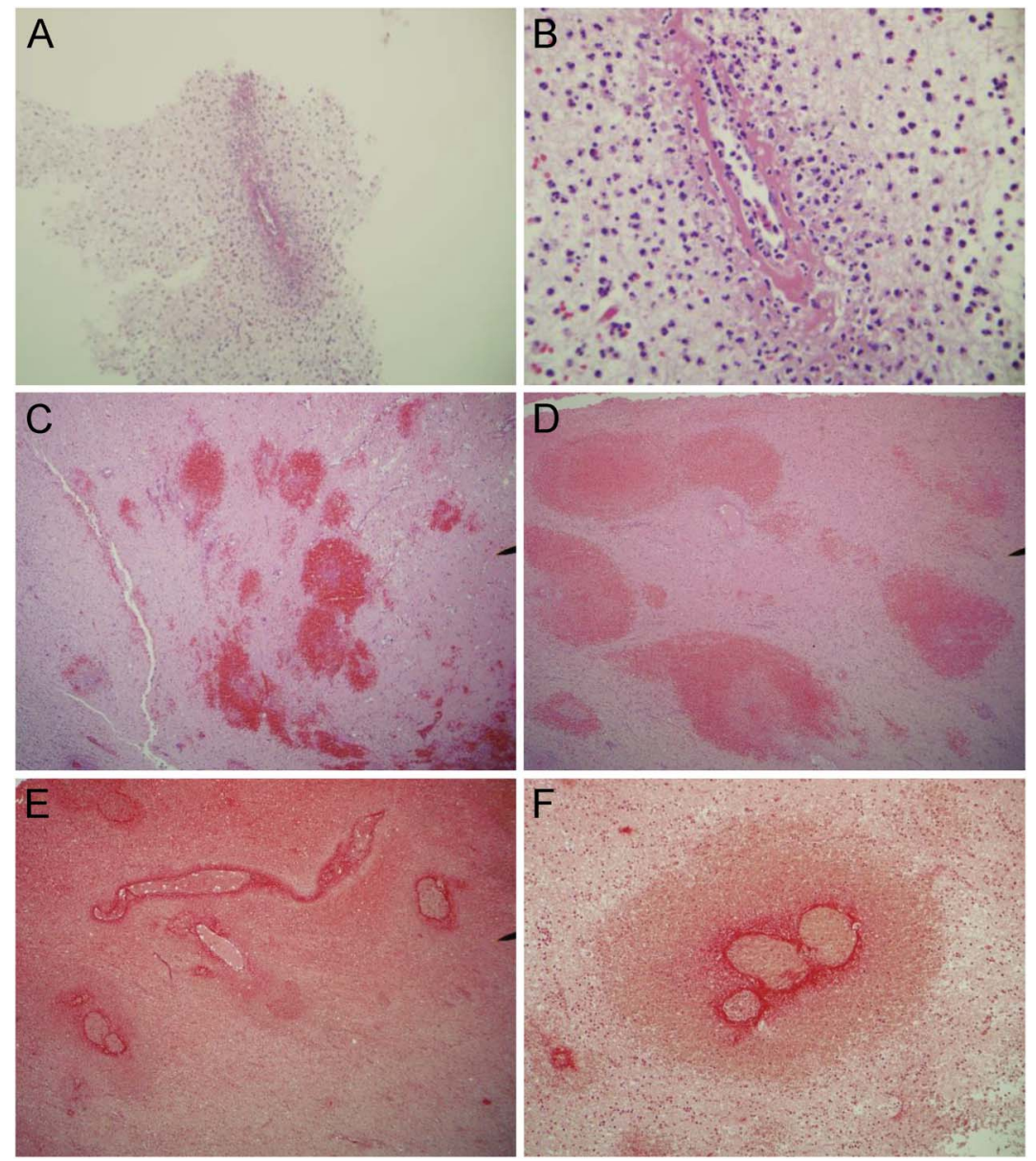

Initial brain biopsy on day 2 of the right frontal region showed acute cerebritis. There was a marked acute inflammatory cell reaction most consistent with an acute infectious process noted in lower $(A)$ and higher $(B)$ magnification. The neutrophil predominance was determined to be consistent with a pyogenic process, although the Gram stain was negative. Silver stain was also negative for fungus. There was no neoplasm, granulomatous inflammation, or vasculitis present. (C, D) Hematoxylin \& eosin stain at autopsy showed punctate, ring-shaped foci of perivascular hemorrhage and edema, localized to the white matter. This was surrounded by inflammation with a predominantly macrophage reaction in the right and left orbital frontal areas as well as right frontal-parietal sections. (E, F) Trichrome stain confirmed fibrinoid necrosis in multiple vessels in the right orbital frontal and frontal-parietal areas. There was no lymphocytic infiltration and no microglial nodules as seen in vasculitis and viral encephalitis, respectively. There was no inflammation in the vessel walls. Thromboemboli, viral cytopathologic effects, foreign abscesses, and granulomas were not seen.

BIOPSY RESULTS Brain biopsy on day 2 of the right frontal lobe showed acute cerebritis as shown in figure 3. There is a marked acute inflammatory cell reaction most consistent with an acute infectious process. The neutrophil predominance was determined to be consistent with a pyogenic process, although the Gram stain was negative. Silver stain was also negative for fungus. There was no neoplasm, granulomatous inflammation, or evidence of vasculitis present.

AUTOPSY RESULTS A full autopsy was performed with the brain being removed and formal-fixed in a routine fashion. The brain weight was $1,600 \mathrm{~g}$. On external examination of the brain, there was hemorrhagic necrosis and edema noted along the right lateral edge of the frontal/temporal/parietal area (figure 2). There was subfalcine herniation and cerebellar tonsillar herniation. There was also uncal herniation noted on the right causing Duret hemorrhages in the pons, which was likely the fatal complication. Hemorrhagic necrosis was seen in the right hemisphere in multiple sections from frontal to temporal lobes. No space-occupying lesion or abscess was noted. Inspection of the vessels showed no evidence of thrombus or embolic events. Inspection of the meninges showed no evidence of infection. Inspection of the right hippocampus showed minute dark hemorrhages in the posterior portion reflecting uncal contusion.

Microscopic examination. There were multiple areas of perivascular ring-like hemorrhages with surrounding inflammation of both acute (neutrophils) but predominantly a chronic macrophage reaction (figure 3). These were seen predominantly in the right and less so in the left orbital frontal areas as well as the right frontal-parietal specimens. No microglial nodules were noted. A multicentric fibrinoid necrosis was seen within these vessels with surrounding edema and hemorrhages noted. These involved predominantly the smaller arteriolar and venule type vessels. No vasculitic changes were present. Examination of the hippocampus, cerebellum, and pons showed evidence of terminal hypoxic ischemic encephalopathy with selective neuronal necrosis. Examination of brainstem showed areas of Duret hemorrhages in midbrain and pons secondary to brain herniation as well as areas of ring-like hemorrhages and perivascular inflammatory macrophage reaction were noted.

Gram and silver stain were performed, which were negative for bacteria and fungi. The trichrome stain confirmed fibrinoid necrosis (figure 3) in multiple vessels of the right orbital frontal and right frontoparietal areas. Staining for ferritin confirmed the presence of macrophages surrounding ring-like hemorrhages. Staining for HSV-1 and HSV-2 was negative.

Immunohistochemistry for myelin basic protein showed areas of reduced staining in a perivascular distribution throughout the white matter (figure 4). The $U$ fibers were spared. There was perivascular edema noted as well as axonal damage. Immunohistochemistry for IgG and IgM showed a perivascular pattern consistent with autoimmune inflammatory reaction or "leaky" vessels. CD68 confirmed macrophage infiltration around these vessels. T cell markers CD3 and CD8 were negative. CD20, a B cell marker, was also negative. 

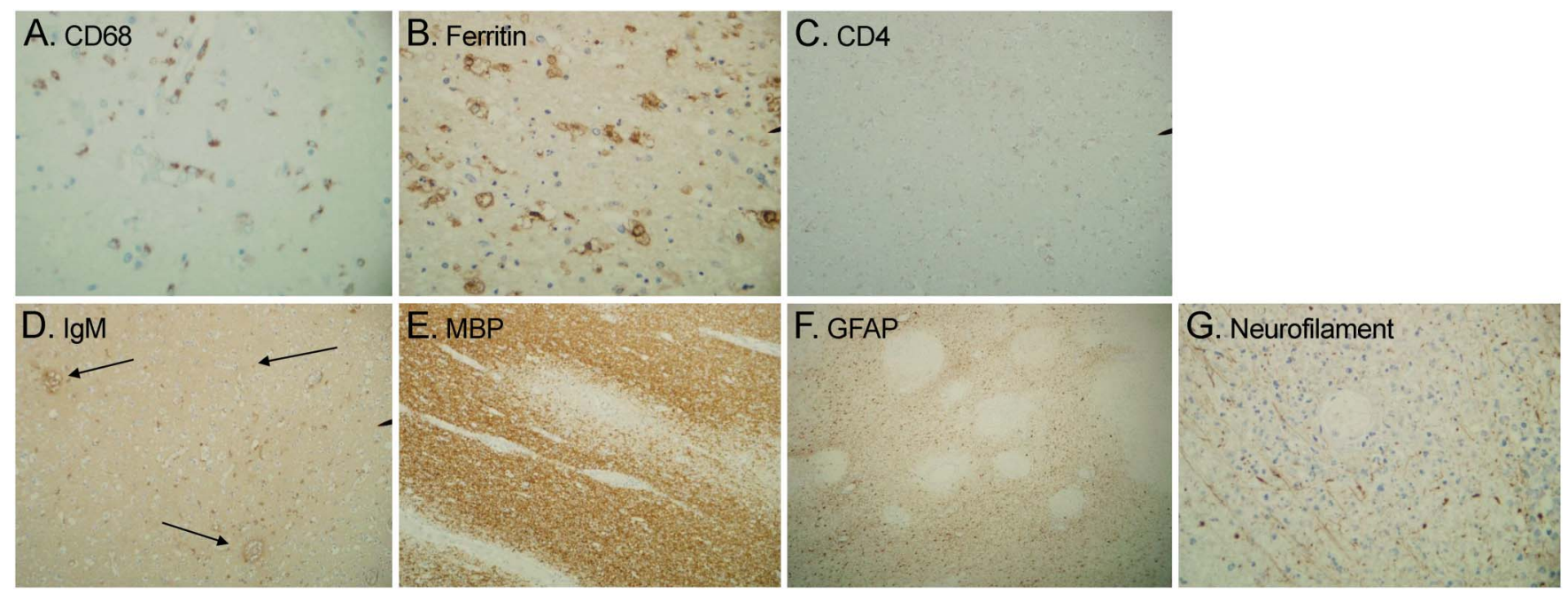

CD68 (A) and ferritin (B) stain showed the presence of scattered microglial cells, foamy macrophages, and rare hemosiderin-laden macrophages. CD4 was negative for T cells (C). Other tests performed include staining T cell markers CD3, CD4, CD5, and CD8, as well as B cell marker CD20 (data not shown), all of which were negative. These results indicated a primarily macrophage reaction vs lymphocytic. Immunohistochemistry for immunoglobulin $\mathrm{G}$ (IgG) and IgM showed a perivascular double ring-like effect consistent with an autoimmune inflammatory reaction or leakage (arrows, D). Immunohistochemistry for myelin basic protein (MBP) showed areas of reduced staining in a perivascular distribution throughout the white matter (E). The $U$ fibers were spared. There was perivascular edema, gliosis, and mild axonal damage seen on glial fibrillary acidic protein (GFAP) (F) and neurofilament stain (G). Of note, neurofilament stain showed minimal axonal damage in contrast to the MBP stain, which was most consistent with demyelination. Herpes simplex virus 1 and 2 staining was negative. Gram stain and silver stain were also performed, which were negative for infection.

We isolated DNA from formalin-fixed brain and lung tissue (figure 5). PCR test for Mycoplasma DNA was positive in the right lung field and the right frontal lobe of the brain (sample taken from the area of hemorrhage).

DISCUSSION Case reports showing both biopsy and full autopsy results from the same case of AHLE are rare. Seven previous autopsies have been reported, however. ${ }^{2-8}$ In this case, the biopsy and full autopsy were performed within 5 days from presentation, which revealed a chronological change that has provided clues to the pathophysiology of this rare disorder. There still remain several areas of uncertainty regarding AHLE. This case not only provides more concrete evidence that $M$ pneumoniae is a trigger but we can also learn more about the pathophysiology including why there were differences seen in the biopsy of the brain vs autopsy at day 5 . In addition, is this truly a demyelinating disorder?

Regarding antigenic infectious causes for AHLE, several have been identified and in this case we confirmed $M$ pneumoniae involving the right lung as the trigger. Since it was first reported in 1941 by Hurst, ${ }^{9}$ AHLE remains a rare disorder with a poor prognosis, and, to date, Epstein-Barr virus, ${ }^{10-13}$ HSV, ${ }^{14,15}$ and $M$ pneumoniae ${ }^{3}$ have been identified as causes. We reported positive DNA via PCR from lung and diseased brain for $M$ pneumoniae (figure 5). This is in keeping with the chest $\mathrm{x}$-ray findings showing atypical pneumonia, the autopsy results showing myocarditis, and positive cold agglutinins test, all in keeping with recent $M$ pneumoniae infection. The significance of identifying Mycoplasma DNA via PCR in brain indicates that brain invasion had occurred. This has been previously described using immunohistochemistry on autopsy specimens from brain tissue in a patient with AHLE. ${ }^{3}$ Three other previous reports of $M$ pneumoniae triggering AHLE have been reported, which showed positive serology including both IgG and IgM, as well as cold agglutinin positivity ${ }^{11,16}$; however, positive serology simply indicates past exposure and is not specific for a recent infection.

In previous studies, it is hypothesized that $M$ pneumoniae triggers a cross-reaction to antigens for myelin to account for the demyelination., ${ }^{3,410}$ However, there is no direct evidence for this. Whether the immune response is toward $M$ pneumoniae or actual neural antigens also remains unclear. Pathologic features include focal hemorrhages with perivascular demyelination. These findings were seen in both the right and left hemisphere in our case, more so on the right in the large area of hemorrhage, as well as small areas in the pons. In areas of vessel wall fibrinoid necrosis, there were perivascular areas of demyelination and edema noted, as shown in figure 4. Immunohistochemistry showed lack of staining for myelin basic protein around vessel walls but the presence of neurofilament staining throughout, which 


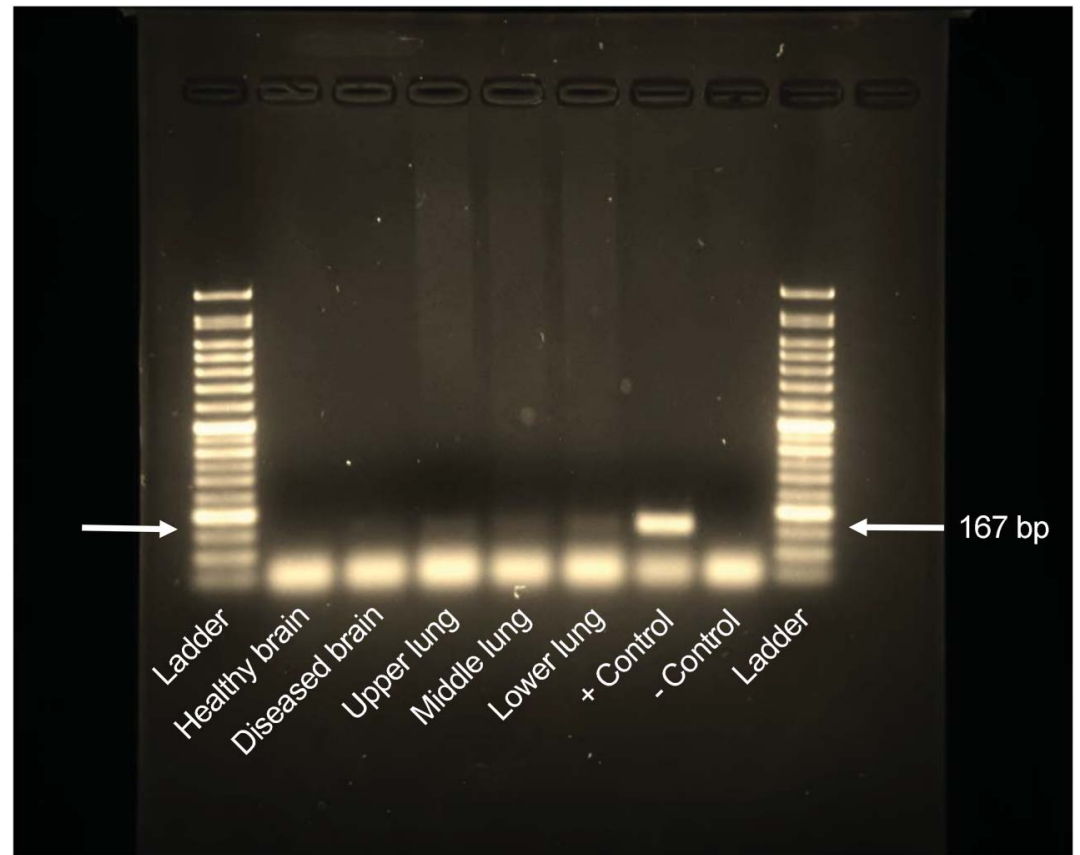

DNA was isolated from the right hemisphere of the brain in an area of hemorrhage and normal brain from the autopsy of our patient as well as the right lung. PCR test for Mycoplasma DNA is shown above. A corresponding 167-base pair (bp) band, as seen in the control, is noted in all the right lung fields (upper, middle, and lower) and diseased brain consistent with amplification of Mycoplasma DNA. No band for Mycoplasma DNA was seen in normal areas of the brain. The results indicate a recent Mycoplasma pneumoniae infection with brain invasion, which ultimately led to Weston Hurst syndrome.

signified that the axons were relatively intact but some demyelination had occurred. Nevertheless, although we have postulated that demyelination had occurred in our case, we were not able to determine whether there was a separate mechanism causing demyelination or if this was a cross-reaction to M pneumoniae as previously proposed. ${ }^{3}$

The core diagnostic feature of AHLE is the fibrinoid necrosis of vessel walls. Although we showed brain invasion by $M$ pneumoniae, a direct infection causing an encephalitis by this bacteria would unlikely cause fibrinoid necrosis and such vessel wall damage at day $5 .{ }^{17}$ This is central to the pathophysiology of AHLE, and the immunologic cascade leading to this terminal event can be postulated to be divided into 2 phases. An initial "Mycoplasma phase" is predominantly a neutrophil reaction with no fibrinoid necrosis of the vessel walls, as seen on the day 2 biopsy result and in a previous study. ${ }^{18}$ This likely represents a direct immunologic reaction to CNS invasion by Mycoplasma pneumonia. This is followed by a quick second phase, an "immune phase," which is macrophage-predominant, leading to degranulation, cytokine release, and ultimately vessel wall necrosis, the fatal response in this disorder. This was seen at day 5 at autopsy in this case and, of note, was previously reported. ${ }^{2,3}$ Further evidence for activation of the innate immune system was proposed in a recent report ${ }^{19}$ that postulated that the complement cascade is involved in the pathogenesis of AHLE. It has been suggested that deposition of immune complexes on vessel walls triggers complement activation and ultimately recruitment of macrophages in this second phase. Whether this second phase represents a distinct autoimmune phase has been hypothesized but to date there is no evidence for immunocomplex deposition or direct activation of complement in this condition. This is in contrast to acute disseminated encephalomyelitis, which is a lymphocytic ( $\mathrm{T}$ cell or humoral B cell) predominant response that we did not see in our case.

Similar to our case, an initial neutrophil response followed by macrophage reactions has been continually reported in previous case reports. ${ }^{2,11,20}$ Unfortunately, the primary neutrophil response with no fibrinoid necrosis of vessel walls obscured the diagnosis at the day 2 biopsy result and the patient was aggressively treated for infection and not an autoimmune reaction on presentation. Survivors of this disorder have rarely been reported. In a previous report, ${ }^{18}$ successful treatment involved quick recognition of the disorder, decompressive craniotomy, followed by 10 treatments of therapeutic plasma exchange leading to a successful outcome with full reversal of presenting neurologic deficits. In another recent study, ${ }^{19} 2$ patients of Filipino descent were shown to have partial complement factor I deficiency and responded successfully to a novel drug, anakinra, an interleukin 1 receptor antagonist. Anakinra can serve to control inflammation via complementmediated effects by reducing interleukin $1 \beta$ signaling and thus is another possible treatment for AHLE that should be explored.

\section{AUTHOR CONTRIBUTIONS}

Rick Magun: manuscript concept and design, performed autopsy, analysis and interpretation of test results, constructed and wrote manuscript. Chris P. Verschoor: performed DNA analysis, figure 5, reviewed manuscript regarding immunologic response. Dawn M.E. Bowdish: critical revision of manuscript for immunologic intellectual content. John Provias: manuscript concept and design, performed autopsy, analysis and interpretation of test results, critical revision of manuscript for intellectual content.

\section{STUDY FUNDING}

No targeted funding.

\section{DISCLOSURE}

The authors have no disclosures. Go to Neurology.org/nn for full disclosure forms.

Received July 14, 2015. Accepted in final form November 3, 2015.

\section{REFERENCES}

1. Dos Santos MP, Martin J, Woulfe J, et al. Autopsy-proven acute hemorrhagic leukoencephalitis in an elderly patient. Can J Neurol Sci 2014;41:99-102. 
2. Gillies CG, Grunnet M, Hamilton CW. Tubular inclusions in macrophages in the brain of a patient with acute hemorrhagic leukoencephalitis (Weston Hurst syndrome). Ultrastruct Pathol 1994;18:19-22.

3. Stamm B, Moschopulos $\mathrm{M}$, Hungerbuehler $\mathrm{H}$, et al. Neuroinvasion by Mycoplasma pneumoniae in acute disseminated encephalomyelitis. Emerg Infect Dis 2008;14:641-643.

4. Donnet A, Dufour H, Gambarelli D, et al. Acute Weston Hurst necrotizing hemorrhagic leukoencephalitis. Rev Neurol 1996;152:748-751.

5. Tshibanda L, Nchimi A, Otte M, et al. Hurst acute haemorrhagic leukoencephalitis: MRI findings [in French]. JBR-BTR 2007;90:290-293.

6. Lann MA, Lovell MA, Kleinschmidt-DeMasters BK, et al. Acute hemorrhagic leukoencephalitis: a critical entity for forensic pathologists to recognize. Am J Forensic Med Pathol 2010;31:7-11.

7. Abou Zeid NE, Burns JD, Wijdicks EF, et al. Atypical acute hemorrhagic leukoencephalitis (Hurst's disease) presenting with focal hemorrhagic brainstem lesion. Neurocrit Care 2010;12:95-97.

8. Pinto PS, Taipa R, Moreira B, et al. Acute hemorrhagic leukoencephalitis with severe brainstem and spinal cord involvement: MRI features with neuropathological confirmation. J Magn Reson Imaging 2011;33:957-961.

9. Hurst EW. Acute hemorrhagic leukoencephalitis: a previously undefined entity. Med J Aust 1941;1:1-6.

10. Hofer M, Weber A, Haffner K, et al. Acute hemorrhagic leukencephalitis (Hurst's disease) linked to Epstein-Barr virus infection. Acta Neuropathol 2005;109:226-230.

11. Francisci D, Sensini A, Fratini D, et al. Acute fatal necrotizing hemorrhagic encephalitis caused by Epstein-Barr virus in a young adult immunocompetent man. J Neurovirol 2004;10:414-417.

12. Befort P, Gaillard N, Roubille C, et al. Hemorrhagic leukoencephalitis linked to Epstein-Barr virus in an adult patient. Clin Neurol Neurosurg 2010;112:829-831.

13. Takeuchi S, Takasato Y, Masaoka H, et al. Hemorrhagic encephalitis associated with Epstein-Barr virus infection. J Clin Neurosci 2010;17:153-154.

14. SF An, Groves M, Martinian L, et al. Detection of infectious agents in brain of patients with acute hemorrhagic leukoencephalitis. J Neurovirol 2002;8:439-446.

15. Martins HM, Teixeira AL Jr, Lana-Peixoto MA, et al. Acute hemorrhagic leukoencephalitis mimicking herpes simplex encephalitis: case report. Arq Neuropsiquiatr 2004;62:139-143.

16. Catalan M, Naccarato M, Grandi FC, et al. Acute hemorrhagic leukoencephalitis with atypical features. Neurol Sci 2009;30:55-57.

17. Payne ET, Rutka JT, Ho TK, et al. Treatment leading to dramatic recovery in acute hemorrhagic leukoencephalitis. J Child Neurol 2007;22:109-113.

18. Ryan LJ, Bowman R, Zantek ND, et al. Use of therapeutic plasma exchange in the management of acute hemorrhagic leukoencephalitis: a case report and review of the literature. Transfusion 2007;47:981-986.

19. Broderick L, Gandhi C, Mueller JL, et al. Mutations of complement factor I and potential mechanisms of neuroinflammation in acute hemorrhagic leukoencephalitis. J Clin Immunol 2013;33:162-171.

20. Bitnun A, Richardson SE. Mycoplasma pneumoniae: innocent bystander or a true cause of central nervous system disease? Curr Infect Dis Rep 2010;12:282-290. 


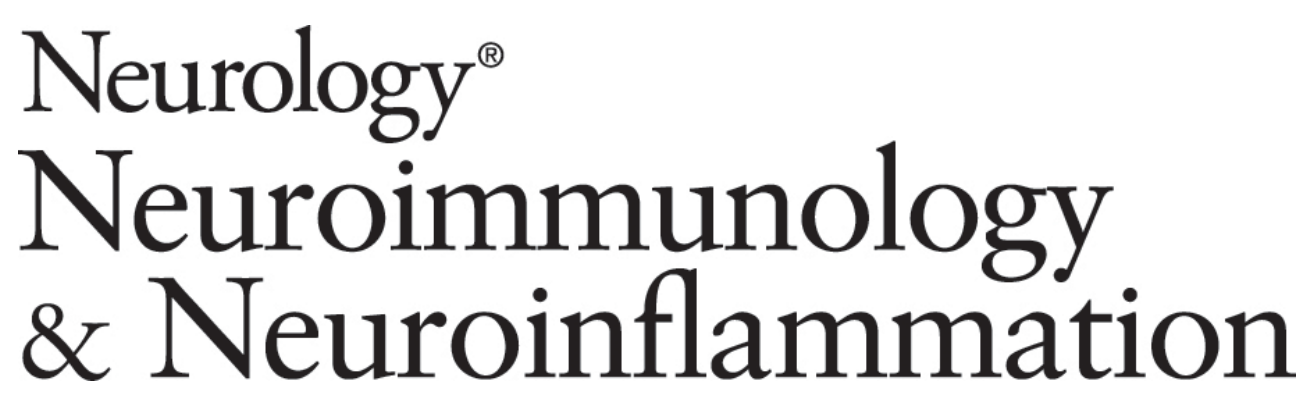

Mycoplasma pneumoniae, a trigger for Weston Hurst syndrome

Rick Magun, Chris P. Verschoor, Dawn M.E. Bowdish, et al.

Neurol Neuroimmunol Neuroinflamm 2016;3;

DOI 10.1212/NXI.0000000000000187

This information is current as of January 21, 2016

Neurol Neuroimmunol Neuroinflamm is an official journal of the American Academy of Neurology.

Published since April 2014, it is an open-access, online-only, continuous publication journal. Copyright $\odot$ 2016 American Academy of Neurology. All rights reserved. Online ISSN: 2332-7812.

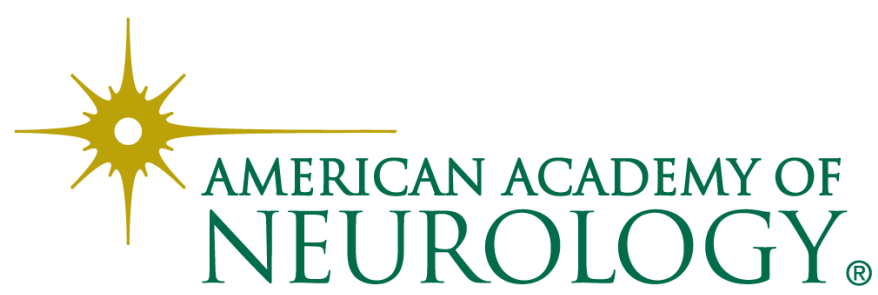




\section{Updated Information \& Services}

References

Citations

Subspecialty Collections

Permissions \& Licensing

Reprints including high resolution figures, can be found at: http://nn.neurology.org/content/3/1/e187.full.html

This article cites 20 articles, 0 of which you can access for free at: http://nn.neurology.org/content/3/1/e187.full.html\#\#ref-list-1

This article has been cited by 1 HighWire-hosted articles: http://nn.neurology.org/content/3/1/e187.full.html\#\#otherarticles

This article, along with others on similar topics, appears in the following collection(s):

Acute disseminated encephalomyelitis

http://nn.neurology.org//cgi/collection/acute_disseminated_encephalo myelitis

Autoimmune diseases

http://nn.neurology.org//cgi/collection/autoimmune_diseases

Bacterial infections

http://nn.neurology.org//cgi/collection/bacterial_infections

Critical care

http://nn.neurology.org//cgi/collection/critical_care

Encephalitis

http://nn.neurology.org//cgi/collection/encephalitis

Information about reproducing this article in parts (figures,tables) or in its entirety can be found online at:

http://nn.neurology.org/misc/about.xhtml\#permissions

Information about ordering reprints can be found online:

http://nn.neurology.org/misc/addir.xhtml\#reprintsus

Neurol Neuroimmunol Neuroinflamm is an official journal of the American Academy of Neurology.

Published since April 2014, it is an open-access, online-only, continuous publication journal. Copyright $\odot$ 2016 American Academy of Neurology. All rights reserved. Online ISSN: 2332-7812.

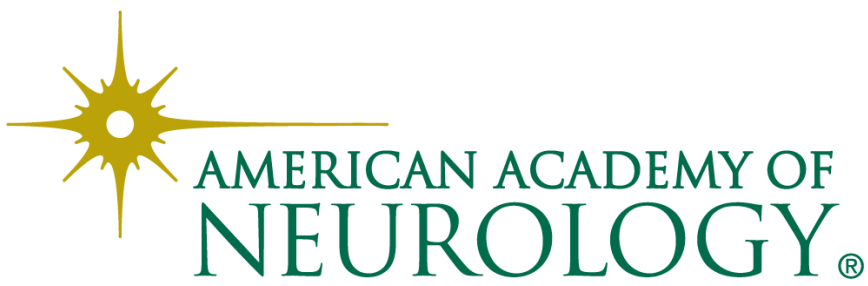

